\title{
Educação popular em saúde e planejamento participativo na Educação Física Escolar
}

Luciana Santos Collier ${ }^{1}$

\section{Resumo}

Este texto tem como objetivo apresentar reflexões sobre as relações entre a Educação Física Escolar e as concepções de promoção da saúde e educação popular em saúde, quando a metodologia do planejamento participativo é utilizada. A investigação foi construída num processo de ação-reflexão-ação e apresentada no diálogo entre o referencial teórico da área e o relato da experiência pedagógica, cujas ações se apoiaram nos pilares: diversidade de conteúdos; desenvolvimento da autonomia e aplicação do conhecimento dentro e fora da escola. Utilizando a metodologia do planejamento participativo, os conhecimentos sobre cultura corporal são ampliados, possibilitando, desta forma, a organização autônoma dos alunos nas experiências vivenciadas em diferentes espaços, dentro e fora da escola. Assim, educação popular em saúde e o planejamento participativo se encontram no diálogo e na problematização, colaborando com o empoderamento comunitário, imprescindível para a promoção da saúde.

\section{Palavras-chave}

Educação Física Escolar. Promoção da Saúde. Diálogo. Problematização. Empoderamento.

\footnotetext{
${ }^{1}$ Doutora em Ensino em Biociências e Saúde pelo Instituto Oswaldo Cruz/Fiocruz, Rio de Janeiro, Brasil, com estágio pós-doutoral em Promoção da Saúde em Escolas, Universidade de La Rioja, Espanha; professora da Universidade Federal Fluminense, Rio de Janeiro, Brasil; membro dos grupos de pesquisa Schools for Health in Europe (SHE) e Clínica em Epidemiologia e Tecnologias Inovadoras em Saúde (Fiocruz). E-mail: lucianacollier@gmail.com.
} 


\title{
Popular health education and participatory planning in School Physical education
}

Luciana Santos Collier ${ }^{2}$

\begin{abstract}
This text aims to present reflections on the relationships between School Physical Education and the concepts of health promotion and popular education in health, when the participatory planning methodology is used. The research was built in a process of actionreflection-action and presented in the dialogue between the theoretical reference of the area and the report of the pedagogical experience, which actions were based on the pillars: diversity of contents; development of autonomy and application of knowledge inside and outside of school. Using the methodology of participatory planning, we broaden our knowledge about body culture and enable the autonomous organization of related experiences that are experienced in different spaces, both inside and outside the school. Thus, popular education in health and participatory planning are found in the dialogue and problematization, present in both and this collaborates with the community empowerment, essential for the promotion of health.
\end{abstract}

\section{Keywords}

School Physical Education. Health Promotion. Dialogue. Problematization. Empowerment.

\footnotetext{
${ }^{2} \mathrm{PhD}$ in Teaching in Biosciences and Health, Oswaldo Cruz Institute/Fiocruz, State of Rio de Janeiro, Brazil, with post-doctoral internship in Health Promotion in Schools, University of La Rioja, Spain; professor at Fluminense Federal University, State of Rio de Janeiro, Brazil; member of the Schools for Health in Europe (SHE) and Clinical Epidemiology and Innovative Technologies in Health (Fiocruz) research groups. E-mail: lucianacollier@gmail.com.
} 


\section{Introdução}

Na década de 1980, a Organização Mundial da Saúde (OMS) criou o Programa Escolas Promotoras da Saúde, visando fortalecer e ampliar a colaboração entre os setores da educação e da saúde e estimular o processo democrático como ferramenta para o desenvolvimento de habilidades necessárias para uma vida saudável (CORDEIRO, 2008). Em 2007, o governo brasileiro adotou as ações das Escolas Promotoras de Saúde como diretrizes para construir o Programa Saúde na Escola (PSE), com a finalidade de contribuir para a formação integral dos estudantes da rede pública da educação básica, por meio de ações de prevenção, promoção e atenção à saúde. A equipe formada pelos profissionais de saúde e da educação teriam a função de fomentar permanentemente o empoderamento de estudantes, professores e funcionários das escolas, com base no princípio básico da promoção da saúde (BRASIL, 2009). Como estratégia intersetorial, o PSE articula suas ações com vistas ao enfrentamento das vulnerabilidades que comprometem o pleno desenvolvimento de crianças e jovens da rede pública de ensino.

Segundo Vieira et al. (2017), para ser um espaço produtor de saúde, a escola deve promover a educação integral e o desenvolvimento de habilidades pessoais, garantindo ambientes saudáveis e protetores, e por meio de ações que reforcem o bem viver. Dentre as estratégias utilizadas para o alcance desses objetivos está a educação em saúde, que cria espaços de diálogo e reflexão sobre comportamentos e hábitos saudáveis, auxiliando os indivíduos a desenvolverem as habilidades que contribuem para o bem viver, promovendo e estimulando a autonomia e a corresponsabilidade, fortalecendo uma vida com mais qualidade (OPAS, 2003). Badziak e Moura (2010) explicam que, embora os comportamentos saudáveis sejam muitas vezes entendidos como uma responsabilidade individual, eles são fortemente influenciados pelos determinantes sociais da saúde (DSS), não podendo ser controlados exclusivamente pelos sujeitos.

No que tange às estratégias pedagógicas de educação em saúde, a Organização PanAmericana da Saúde (OPAS) recomenda a utilização de metodologias participativas pelo professor, que deve inserir no cotidiano escolar conteúdos que fomentem a reflexão crítica, auxiliando o indivíduo a avaliar a sua realidade, reconhecer potencialidades e construir um cenário melhor para sua vida. Quando os conteúdos estão articulados à realidade, tendo como orientação metodológica, o diálogo e a reflexão crítica - características do planejamento participativo - torna-se possível auxiliar os alunos a fazer escolhas mais saudáveis. A escola que estimula o diálogo contribui com o fortalecimento de habilidades necessárias para o 
desenvolvimento de estilos de vida saudáveis, agindo em prol da inclusão e da promoção da saúde. Vieira et al. (2017) concluem que o desenvolvimento de relações democráticas no espaço escolar pode colaborar com a construção de um entorno escolar saudável.

Articulado com esse contexto, este texto tem como objetivo apresentar algumas reflexões sobre as possíveis relações entre a Educação Física Escolar e as concepções de promoção da saúde e educação popular em saúde quando a metodologia do planejamento participativo é utilizada nas aulas.

\section{Metodologia: desenvolvimento da pesquisa}

Segundo Faria, Bracht e Machado (2010), o professor-pesquisador de Educação Física que atua e pesquisa a escola básica pública no Brasil não goza de reconhecimento, nem da sociedade, nem da comunidade acadêmica. Caparroz e Bracht (2007) afirmam que a "onda" cientificista provocou, na Educação Física, uma desvalorização da discussão pedagógica. As questões do cotidiano escolar perderam prestígio, reforçando a dicotomia entre os "teóricos" e os "práticos".

Betti (2005) acrescenta que os professores de Educação Física Escolar passaram a não se reconhecer nos conhecimentos produzidos pelos pesquisadores da área, mas acreditam que há algo importante em suas práticas pedagógicas. Para reverter essa lógica, o autor incentiva o desenvolvimento de pesquisas no "chão da escola", a fim de contribuir para o enriquecimento das práticas pedagógicas. Caparroz e Bracht (2007) encorajam os docentes a buscarem compreender e construir sua autoria, baseada no processo contínuo de ação-reflexão-ação no cotidiano da prática pedagógica. Essa autoria vincula-se a um exercício incessante de reflexão sobre o desenvolvimento da prática pedagógica e implica/demanda um processo de investigação e escrita. Indo mais além, esses autores afirmam que o professor deve agir de forma autônoma e crítica como sujeito e autor de sua pedagogia. Não deve aplicar teoria na prática e, sim, reconstruir e reinventar sua prática com referência em ações/experiências e em reflexões/teorias.

Nesse sentido, este texto é um relato de experiência, no qual as observações e argumentos apresentados fazem parte de um longo processo de ação-reflexão-ação, em que a prática pedagógica foi requerendo um aprofundamento cada vez maior no referencial teórico e, por outro lado, esse aprofundamento foi gerando novas reflexões e práticas pedagógicas. No desenvolvimento do estudo, foram utilizados alguns autores que discutem a Educação 
Física Escolar, a promoção da saúde e a educação popular em saúde, para explicar as interfaces desses conceitos. Dialogando com esses mesmos autores, a metodologia do planejamento participativo é apresentada, explicando como vem sendo construída em parceria com os alunos no cotidiano das aulas. Para concluir, demonstram-se as relações existentes entre a metodologia do planejamento participativo e a inserção do tema da promoção da saúde na educação física escolar.

\section{Saúde e promoção da saúde: ampliando os conceitos}

Moreira et al. (2009) dizem que, pensando a saúde de forma ampla, que considera o homem em suas diversas dimensões, a educação em saúde deve comportar uma dimensão correlata, que também considere suas diferentes dimensões, incluindo os aspectos simbólicos da vida humana. Badziak e Moura (2010) vão além e acrescentam que, partindo de uma definição mais abrangente de saúde, não reduzida à esfera biológica, todas as medidas a ela relacionadas devem ser integrais, ou seja, devem buscar contemplar suas diferentes dimensões.

A despeito dos avanços já alcançados na própria conceituação do termo saúde, Moreira et al. (2009) ressaltam que a educação em saúde tem conservado uma prática ainda reducionista que, além de considerar a saúde apenas como resultado de processos biológicos, também considera o saber médico como o único passível de estabelecer "a verdade" sobre o processo saúde-doença-cuidado. Esse reducionismo caracteriza tanto a visão de saúde centrada no modelo médico-curativo, como também uma visão comportamentalista de homem, que pauta a ação educativa em saúde na modificação de comportamentos (CARVALHO, 2004). Nessa lógica de raciocínio, tais comportamentos- são compreendidos como decorrentes "de um déficit cognitivo e cultural, cuja superação pode se dar por meio de informações científicas e saberes provenientes do exterior" (GAZZINELI et al., 2005, p. 3), caracterizando a hierarquização de saberes, sendo o saber médico-científico mais valorizado que o saber popular.

Com a intenção de superar esse reducionismo, costuma-se utilizar o conceito de promoção da saúde, que abrange os diferentes fatores sociais que afetam a saúde. Segundo Moreira et al. (2009) essa noção está baseada no conceito ampliado de saúde, considerado como um estado positivo e dinâmico de busca de bem-estar. Para Carvalho (2004) o "empoderamento comunitário", surge como categoria central da promoção da saúde, pois 
suscita a elaboração de estratégias que promovam a participação, visando ao aumento do controle sobre a vida por parte dos sujeitos e comunidades, na luta por mais justiça social e qualidade de vida.

Apesar de ajudar a pensar de forma ampliada, a noção de promoção da saúde pode representar uma "armadilha". Verdi e Caponi (2005) destacam nela um enfoque comportamental, relacionado aos hábitos e estilos de vida e outro enfoque ligado à qualidade de vida, referindo-se aos determinantes gerais das condições de vida e saúde da sociedade. No primeiro, promover a saúde estaria resumido a transformar ou alterar comportamentos individuais de risco e, no segundo, seria mudar padrões de alimentação, habitação, saneamento, trabalho, educação, o apoio social e delinear um estilo de vida responsável. Neste, adota-se uma visão coletiva no enfrentamento da questão da saúde, com o olhar focado no ambiente físico, social, político, econômico, cultural, o que ainda não é suficiente para garantir uma mudança de paradigma. Permanecem as ideias de culpabilização do indivíduo/sociedade e de subalternidade às medidas hegemônicas médico-centradas, que visam determinar quais os comportamentos "adequados", independentemente da inserção sócio histórica e cultural do indivíduo, o que gera a manutenção da dependência e não a construção da autonomia.

\section{Compreendendo a educação popular em saúde}

A fim de vislumbrar ideias mais propositivas, Meyer et al. (2006) propõem que a educação em saúde deve buscar construir respostas sociais significativas, criando oportunidades de reflexão crítica e interação dialógica entre sujeitos sociais. Essa compreensão não desconsidera a possibilidade de os programas de educação em saúde proverem informações básicas sobre diversos tópicos relacionados à saúde, desde que contemplem o direito a tomar decisões informadas. O que precisa ser lembrado é que elementos de informação científica não são suficientes para aumentar a competência e/ou a liberdade de decisão, relacionadas às práticas de saúde cotidianas e que as mudanças comportamentais são um produto muito raro dos projetos educativos elaborados sob uma perspectiva informativa (MEYER et al., 2006).

Inspirados em Paulo Freire, Moreira et al. (2009) propõem a valorização do empoderamento comunitário e a "conscientização" como estratégias de educação em saúde. Os autores defendem a "conscientização" não no sentido vertical, de convencimento da 
necessidade de se empoderar (o que caracteriza uma "educação bancária"), mas o desenvolvimento de ações educativas, que visam à reflexão por parte dos sujeitos e das comunidades, para uma ação crítica sobre a sua realidade de saúde. Nesse sentido, a “conscientização" se dá pela necessidade de se envolver e participar na definição e controle de ações coletivas para a melhoria da qualidade de vida (CARVALHO, 2004, p. 675).

Nessa perspectiva, a educação em saúde se une às ideias de educação popular propostas por Freire (2005, p. 79), que partem do pressuposto de que "os homens se educam em comunhão, mediatizados pelo mundo". A educação popular em saúde supera a contradição educador-educandos, possibilitando uma "relação dialógica", perpassando a troca de saberes científicos e populares, relacionados ao processo saúde-doença. Além disso, a proposta se funda na concepção de educação problematizadora, estimulando a criatividade, a reflexão e a ação de transformação da realidade dos sujeitos, comprometida com sua libertação. Para Moreira et al. (2009), o objetivo que se pretende atingir é a autonomia, como princípio basilar da prática educativa. Em sua dimensão libertadora, a educação popular em saúde iguala os sujeitos que aprendem e os que ensinam, bem como, compreende o ato de ensinar como uma forma de intervenção no mundo. Por isso, exige-se disponibilidade para o diálogo, respeito à autonomia e liberdade de escolha.

\section{Relacionando Educação Física Escolar e educação popular em saúde}

Os conteúdos referentes à saúde sempre tiveram seu espaço nas aulas de Educação Física Escolar. Especificamente no Brasil, o tema saúde sempre esteve presente, seja como objeto/objetivo principal ou secundário das propostas curriculares (OLIVEIRA; GOMES; BRACHT, 2014). De acordo com Oliveira (2005), no contexto mais geral da sociedade, o conceito de saúde está deixando de ser pensado apenas na esfera (restrita) biológica, e as questões culturais e sociais vêm ganhando espaço nas discussões (ampliadas) sobre a qualidade da vida. Almeida, Oliveira e Bracht (2016) afirmam que a contribuição primordial da Educação Física Escolar no processo de educação em saúde se constitui no acesso pedagogizado e crítico às práticas da Cultura Corporal de Movimento, de forma que sua intervenção pedagógica não se reduza a exercitação corporal abstrata e naturalizada das práticas corporais. Apesar desse deslocamento no plano conceitual, parece haver um descompasso em relação à ampliação do conceito de saúde e a atuação de muitos professores de Educação Física, que ainda pautam suas ações pedagógicas na tradição dos postulados 
biomédicos (DEVIDE, 2003). A grande dificuldade para realizar esse deslocamento também nas ações e práticas pedagógicas, passa pela vinculação do conceito de saúde com o de aptidão física, enquanto instrumento que leva à "boa" saúde, sem relação com a cultura corporal.

Knuth, Azevedo e Rigo (2007) alertam que o desafio que está posto é o de construção de uma proposta de inserção do tema saúde na grade curricular da Educação Física Escolar, a partir de uma postura crítica e desafiadora, fortalecendo o diálogo com outras disciplinas e áreas do conhecimento numa perspectiva política e histórico-cultural. Para Almeida, Oliveira e Bracht (2016) o desafio consiste em transformar não somente o saber sobre a saúde (plano conceitual, discurso sobre saúde), mas também um "saber-fazer" (plano das práticas), de forma a permitir aos alunos problematizar, complexificar e ampliar "a compreensão, a atenção, a experimentação (corporal) dos elementos da Cultura Corporal de Movimento na direção da promoção da saúde" (ALMEIDA; OLIVEIRA; BRACHT, 2016, p. 94).

Avançando nas propostas educativas, Kottmann e Küpper (1999 apud OLIVEIRA; GOMES; BRACHT, 2016) defendem uma perspectiva, cuja ideia central é o desenvolvimento de competências que levem os alunos a agir de forma responsável e coerente em relação à saúde individual e coletiva, aprendendo a obter consequências desejáveis sobre a saúde e evitar as consequências indesejáveis ao longo da vida. Segundo Oliveira, Gomes e Bracht (2014) se os alunos tiverem, durante o período escolar, experiências diversificadas e significativas no movimentar-se, que enriqueçam suas vidas e forneçam a elas um sentido, não estaremos apenas preenchendo um requisito fundamental da educação, mas também, colaborando com a promoção da saúde para toda a vida. Para esses autores, nas aulas de Educação Física, devem ser oferecidas oportunidades de transferência dessas competências para situações fora das aulas e fora da escola. Farinatti e Ferreira (2006) acrescentam que a saúde na Educação Física Escolar, exige pensar a vida em suas múltiplas dimensões, incluindo direitos e necessidades individuais e coletivos. Para esses autores a inserção do tema saúde nas aulas de Educação Física Escolar deve incluir reflexões e práticas que levem os estudantes a avaliarem os espaços de lazer disponíveis à prática da atividade física, as relações entre estilos de vida e condições de vida das comunidades, etc.

Partindo dos pressupostos apontados acima, apoiada na metodologia do planejamento participativo, na qual os alunos colaboram com o planejamento, desenvolvimento e avaliação das aulas, venho buscando aprimorar as ações de ensino em Educação Física Escolar, ampliando a compreensão do conceito de saúde, aliado à formação crítica do cidadão, com desenvolvimento da autonomia na escolha e organização de atividades físicas para a vida. As 
ações se apoiam em três pilares: diversidade de conteúdos; desenvolvimento da autonomia e aplicação do conhecimento dentro e fora da escola. Nessa sequência pedagógica ampliamos os conhecimentos dos alunos sobre a cultura corporal e possibilitamos que eles organizem autonomamente as experiências relacionadas a esses conhecimentos de acordo com suas demandas, vivenciando esses conhecimentos, dentro e fora da escola.

\section{Relato da experiência: o desenvolvimento do planejamento participativo}

Caparroz e Bracht (2007) afirmam que não devemos basear nossa prática pedagógica, única e exclusivamente, em certezas, em modelos ideais, em receitas universais, em verdades "absolutas". Dessa forma, o que vamos apresentar é uma experiência que vem dando bons resultados e que abre a possibilidade de refletir sobre as relações entre educação física escolar e promoção da saúde, na perspectiva da educação popular em saúde. Não pretendemos apontar certezas, nem verdades, mas uma proposta dinâmica, que está viva e em constante transformação, sempre em busca de novas alternativas e soluções. Na medida em que os participantes vão modificando, trazendo novas ideias e sugestões, a proposta também se modifica.

O planejamento participativo nas aulas de educação física é uma metodologia de ensino que incentiva a participação dos alunos no planejamento das aulas, escolhendo, organizando e desenvolvendo os conteúdos e atividades, bem como avaliando todo o processo. A partir dessas ideias, o planejamento participativo vem sendo utilizado no sentido de ampliar o diálogo entre a educação física escolar e a promoção da saúde, estimulando a participação ativa nas aulas, fomentar a cidadania e, consequentemente colaborando com a libertação e transformação da sociedade, incluindo a luta por melhores condições de saúde. Essa proposta se concretiza nos seguintes pilares: diversidade de conteúdos nas aulas; desenvolvimento da autonomia e aplicação do conhecimento dentro e fora da escola.

A proposta inicia com uma sondagem para saber o que os alunos conhecem sobre a cultura corporal. Betti (2005) alerta que o jogo/brinquedo praticado livremente pelos alunos é um dos nascedouros da cultura humana e alimento para sua ampliação. Nesse sentido, devemos trabalhar a partir desse marco, sem confundir o ponto de partida com o de chegada. Partir do que o aluno sabe para construir novos conhecimentos é uma estratégia bastante utilizada na escola básica. A diferença é que no planejamento participativo, os alunos continuam, a partir da troca de saberes, a construir coletivamente o conhecimento. $\mathrm{O}$ 
professor, apesar de participar do processo, vai deixando de centralizar as decisões. Inicialmente os alunos esperam que o professor tome as decisões. Ao longo do processo eles vão percebendo a importância da sua participação e responsabilidade na tomada de decisões para o desenvolvimento das aulas.

Após a sondagem inicial, o professor organiza por temáticas as atividades que os alunos sugeriram, elaborando uma lista de votação para cada tema. A segunda etapa consiste na elaboração do planejamento, por meio de assembleias, em que os alunos votam nas atividades que querem desenvolver nas aulas. Importante lembrar que o professor, como membro desse grupo, também participa dando sugestões, opiniões, dividindo experiências prévias ou justificando os momentos em que sua decisão precisa ser soberana. Segundo Moreira et al. (2009) essa proposta se aproxima da educação problematizadora, na qual o desenvolvimento do conteúdo programático torna-se uma construção resultante do diálogo e passa a ser organizado a partir das demandas dos alunos.

Betti (2005) defende que devemos buscar saber de onde vem o "novo", pois a cultura corporal de movimento não é estática, não apenas reproduz os jogos, os esportes, as danças, mas os produz, os transforma, os cria e recria. Portanto, na terceira etapa, cada turma ao longo das aulas vai reestruturar as atividades, adaptando-as às possibilidades do grupo, sem preocupação com gestos e técnicas rígidas e específicas. Nesse momento, a presença do professor é fundamental, problematizando as situações vividas durante as atividades, relacionando com situações do cotidiano, bem como levando os alunos a encontrarem soluções para as dificuldades na realização das atividades. Faria, Bracht e Machado (2010) reforçam a importância de que as aulas não sejam resumidas à exigência de reprodução dos modelos de movimentos estereotipados das práticas corporais, mas que sejam caracterizadas pela relação dialógica estabelecida entre professor-aluno, considerando os alunos como coautores do processo educacional.

O processo de coautoria nas aulas possibilita aos alunos a busca da autonomia estruturada na liberdade de criação (FARIA; BRACHT; MACHADO, 2010). Por esse motivo, a intenção é de fazê-los participar cada vez mais ativamente da concepção e desenvolvimento das aulas. Partimos de pequenas decisões coletivas, primeiro para organizar as atividades das aulas, depois para resolver problemas que surgem durante a sua experimentação. Com isso desenvolvemos nos alunos a capacidade de organizar aulas, individualmente ou em grupos, a partir de um tema ou conteúdo, também sugerido por eles. Outra experiência muito gratificante é quando conseguimos orientá-los na concepção e desenvolvimento de eventos escolares diversos. A ideia costuma partir deles mesmos, quando começam a perceber sua 
capacidade de organização coletiva. O professor vai apenas orientando, lembrando alguns detalhes, colaborando na construção do evento. Para Faria, Bracht e Machado (2010) as atividades de criação mobilizam os alunos em direção à solução de problemas, além de fomentarem sua autonomia.

Morshbacher e Marques (2013) explicam que a capacidade de dialogar, enquanto competência comunicativa, além de imprescindível na prática pedagógica, é elemento fundamental no processo de formação de sujeitos críticos e emancipados. Por isso, a metodologia agrega o hábito de conversar com os alunos no início da aula para apresentar a proposta do dia (atividades, objetivos e temas escolhidos previamente por eles), durante as atividades (sempre que se faz necessário), bem como a conversa final (para avaliar o desenvolvimento da aula). Faria, Bracht e Machado (2010) explicam que procedimentos como esse rompem com a ideia de que uma "aula teórica" de Educação Física teria que ser desenvolvida em uma sala de aula, distanciada das situações vivenciadas dos elementos da cultura corporal de movimento. Dessa forma, rompe também com o entendimento de que promover discussão e reflexões com os alunos sobre os conteúdos tratados em aula seria "roubar tempo" de movimento ou de atividade física.

Prosseguindo no desenvolvimento da metodologia, a avaliação das aulas, do desenvolvimento dos trimestres e anos letivos e a autoavaliação são ações que nos ajudam a avançar no processo democrático. Diariamente, a avaliação final da aula é feita por meio de conversa informal, registrando no diário de classe, qualquer situação relevante ou alterações no planejamento, decididas coletivamente. Essa relação de coautoria provoca o deslocamento da centralidade ocupada pelo professor, bem como implica a valorização do repertório cultural dos alunos (suas experiências) e diversificação das práticas corporais de movimento. (FARIA; BRACHT; MACHADO, 2010).

Uma avaliação individual e escrita é feita ao final de cada trimestre e ao final do ano letivo, quando os alunos apontam o que foi positivo e negativo, além de darem sugestões para as etapas seguintes. Os pontos positivos e negativos e as sugestões são utilizados na organização do trimestre ou do ano seguinte. Desta forma, o processo de avaliação vai retroalimentando o planejamento participativo, sem tirar a importância do diálogo permanente durante todas as aulas. Os alunos também fazem uma autoavaliação, dizendo como foi a sua participação durante o período. Essa autoavaliação, além de compor a nota do aluno naquela etapa, colabora com o desenvolvimento da responsabilidade e autonomia. De uma forma geral, os alunos relatam boa afinidade com o planejamento participativo, bem como sugerem muitas atividades criativas e inovadoras, que fogem do convencional das aulas de Educação 
Física. Assim contemplamos os dois primeiros pilares da proposta, que são: a diversificação das aulas e o desenvolvimento da autonomia.

Como consequência da diversificação das atividades e do fomento à participação autônoma, os alunos demandam mais aulas externas em espaços públicos de lazer, em que possam experimentar as atividades que realizam nas aulas, bem como outras práticas corporais diferenciadas. Essa etapa da proposta surgiu da demanda dos próprios alunos que, ao longo dos anos, em suas avaliações escritas solicitaram insistentemente que aulas de Educação Física ocorressem em espaços fora da escola. Faria, Bracht e Machado (2010, p. 18) avaliam que "as práticas educativas encontram na experiência uma possibilidade de criar uma interface com as situações relacionadas às práticas sociais fora da escola, ou seja, as práticas do mundo".

É na experiência de levar o conhecimento construído coletivamente dentro da escola para o espaço público de lazer que o aluno observa as limitações impostas pelos determinantes sociais da saúde e reflete sobre as possibilidades de superação das iniquidades sociais. As dificuldades no acesso, a má conservação, a insegurança, a ocupação arbitrária dos espaços públicos, são alguns exemplos de fatores limitantes, que impedem os adolescentes das camadas populares a frequentarem os espaços públicos de lazer. São temas relacionados à promoção da saúde bastante recorrentes nas aulas externas.

Para Faria, Bracht e Machado (2010), o caráter problematizador da metodologia do planejamento participativo possibilita os processos de abertura às experiências e a reflexão conceitual, no sentido de levar à formação do pensamento crítico sobre os elementos da cultura corporal de movimento, que se encontram intimamente relacionados com a promoção da saúde. Cabe ressaltar que o caráter problematizador só é possível a partir da postura dialógica do docente, considerando o aluno como sujeito no processo de ensinoaprendizagem.

\section{Considerações: o planejamento participativo como possibilidade de inserir o tema da promoção da saúde nas aulas de educação física}

O primeiro pilar da proposta de trabalho apresentada é a diversificação das atividades. A utilização das sugestões dos alunos nas aulas e o amplo diálogo na tentativa de resolução de problemas contribuíram de forma importante para o desenvolvimento das diferentes temáticas e atividades. Tal estratégia aproxima a proposta das concepções críticas da Educação Física e 
da promoção da saúde, que defendem uma visão mais humanizada e multideterminada da educação e da saúde.

Sob esse ponto de vista, concordando com Meyer et al. (2006), para compreender os sujeitos em sua totalidade, o processo educativo em saúde precisa estar centralizado na troca de saberes, promovendo a construção e veiculação de conhecimentos e práticas relacionados aos distintos modos de viver de forma saudável. Daí a necessidade de ouvir e dialogar com os alunos, escutar e acatar suas sugestões para as aulas, estimular também que conversem e troquem conhecimentos entre eles, a fim de, não apenas diversificar as atividades e os conteúdos das aulas, mas aumentar as possibilidades de criação de seus próprios modos saudáveis de viver. Para nos aproximarmos da dimensão libertadora da educação popular em saúde não podemos focar somente na troca de saberes e experiências, mas também permitir aos sujeitos associarem a saúde ao resultado das suas condições de vida.

Na educação em saúde, sob a ótica libertadora, professor e aluno são sujeitos do processo educativo. Para Meyer et al. (2006), as informações devem ser compartilhadas de modo a contribuir para o desenvolvimento da autonomia e do empoderamento, que possibilitem a transformação da realidade de saúde dos sujeitos e suas comunidades. Partindo desse pressuposto, de acordo com o segundo pilar da proposta - desenvolvimento da autonomia -, fomentamos nos alunos a reflexão sobre propostas de ação sobre a realidade de saúde, deles mesmos e das comunidades nas quais estão inseridos. Se num primeiro momento precisamos criar condições para que pensem sobre essas propostas de ação, depois de algum tempo são eles que apresentam suas propostas, precisando somente de alguma ajuda para organizá-las. Aproximando essas ideias da estratégia de "empoderamento comunitário" na promoção da saúde, defendida por Carvalho (2004), concordamos que mais do que repassar informações e induzir determinados comportamentos, precisamos dinamizar as reflexões dos sujeitos e coletivos sobre os problemas característicos da vida em sociedade, priorizando a contribuição para a tomada de decisões, o desenvolvimento da consciência crítica e o aumento da capacidade de intervenção sobre a realidade.

Na visão de Freire (2005), o ato de ensinar deve estar relacionado à educação como forma de intervenção no mundo. Dessa forma, o terceiro pilar da proposta se concentra na aplicação do conhecimento construído em espaços fora da escola. Muitas vezes a prática corporal ou atividade física que o aluno mais tem afinidade não está acessível a ele, por motivo econômico, social, estrutural etc. Essa exploração do espaço público resolve algumas dessas dificuldades e abre precedente para refletir com os alunos sobre "as contradições de uma situação existencial, concreta, presente, para que, partindo de um problema real, o sujeito 
se sinta desafiado e busque uma resposta, no nível intelectual, mas, sobretudo, no nível da ação" (MOREIRA et al., 2009, p. 517). Quando possibilitamos ao aluno a vivência de uma prática corporal com a qual ele se sente motivado e tem prazer em realizar, precisamos também criar condições para que ele se sinta capaz de reivindicar o acesso a essa prática.

Carvalho (2004) acrescenta a nossa reflexão que, se preconizamos uma promoção da saúde que busca a ampliação da autonomia e empoderamento do sujeito, não podemos deixar de fora as discussões sobre as relações desiguais de poder que interferem nas condições de saúde da sociedade e que se constituem as raízes estruturais da iniquidade na saúde. Tais pressupostos convergem com as ideias do planejamento participativo nas aulas de educação física, na medida em que estimulamos o aumento da capacidade dos sujeitos e coletivos para definirem, analisarem e atuarem sobre seus próprios problemas, relacionados a qualquer esfera da vida.

Vemos, então, alguns princípios fundamentais da educação popular em saúde presentes em nossa proposta de planejamento participativo. Os conhecimentos dos alunos sobre as práticas corporais são valorizados e considerados como ponto de partida para o processo educativo. Além disso, o planejamento participativo tem como elementos fundantes o diálogo e a educação problematizadora, fomentando um pensar crítico sobre os elementos da cultura corporal de movimento. Cada aluno se reconhece como sujeito ativo no processo de ensino-aprendizagem, agindo sobre as práticas corporais, apropriando-se delas, transformando-as e sendo por elas transformado (FREIRE, 2014).

Com as aulas externas em espaços públicos, priorizamos a problematização dos conceitos relacionados à qualidade de vida e saúde, amplamente divulgados na sociedade, permitindo, assim, desvelar os determinantes sociais, políticos, econômicos e ideológicos que os configuram, possibilitando pensar alternativas para reverter os problemas advindos das características discriminatórias, excludentes e opressoras relacionadas ao tema. Reconhecer esse movimento é uma forma de libertação, no sentido de conscientizar os alunos das diferentes formas de lutar pela transformação da realidade social.

\section{Referências}

ALMEIDA, U. R.; OLIVEIRA, V. J. M.; BRACHT, V. Educação física escolar e o trato didático-pedagógico da saúde: desafios e perspectivas. In: WACHS, F.; ALMEIDA, U. R.; BRANDÃO, F. F. F. (org.) Educação física e saúde coletiva: cenários, experiências e artefatos culturais. Porto Alegre: Rede UNIDA, 2016. Doi: 10.18310/9788566659542. 
BADZIAK, R. P. F.; MOURA, V. E. V. Determinantes sociais da saúde: um conceito para efetivação do direito à saúde. Revista de Saúde Pública de Santa Catarina, Florianópolis, v. 3, n. $1, \quad$ p. 69-79, 2010. Disponível em: http://revista.saude.sc.gov.br/index.php/inicio/article/view/51/114. Acesso em: 20 maio 2019.

BETTI, M. Sobre teoria e prática: manifesto pela redescoberta da educação física. Revista Digital, Buenos Aires, v. 90, 2005. Disponível em: https://www.efdeportes.com/efd91/ef.htm. Acesso em: 10 abr. 2018.

BRASIL. Ministério da Saúde. Secretaria de Atenção à Saúde. Departamento de Atenção Básica. Saúde na Escola. Brasília: Ministério da Saúde, 2009. Disponível em: http://bvsms.saude.gov.br/bvs/publicacoes/cadernos_atencao_basica_24.pdf. Acesso em: 17 mar. 2018.

CAPARROZ, F. E.; BRACHT, V. O tempo e o lugar de uma didática da educação física. RBCE [on-line], Brasília, v. 28, n. 2, p. 21-37, 2007. Disponível em: http://www.redalyc.org/articulo.oa?id=401338529003. Acesso em 10 abr 2018.

CARVALHO, S. R. As contradições da promoção à saúde em relação à produção de sujeitos e a mudança social. Ciência \& Saúde Coletiva, Rio de Janeiro, v. 9, p. 669-678, 2004. Doi: 10.1590/S1413-81232004000300018.

CASTELLANI FILHO, L. Educação física no Brasil: a história que não se conta. 14. ed. Campinas: Papirus, 2007.

COLLIER, L. S. Gestão democrática na escola pública: possibilidades de práticas coletivas no ensino de Educação Física Escolar. 2009. 95 f. Dissertação (Mestrado em Educação, Cultura e Comunicação) - Universidade do Estado Rio de Janeiro, Rio de Janeiro, 2009.

CORDEIRO, J. C. A promoção da saúde e a estratégia de cidades saudáveis: um estudo de caso em Recife, Pernambuco. 2008. 262 f. Tese (Doutorado em Saúde Pública) - Fundação Oswaldo Cruz, Recife, 2008.

DEVIDE, F. P. A educação física escolar como via de educação para a saúde. In: BAGRICHEVSKY, M.; PALMA, A.; ESTEVÃO, A. (org.). A saúde em debate na educação física. Blumenau: Edibes, 2003. p. 137-150.

FARIA, B. A.; BRACHT, V.; MACHADO, T. S. Inovação pedagógica na educação física: o que aprender com práticas bem-sucedidas? Ágora para la Educación Física y el Deporte, Valladolid, v. 12, n. 1, p. 11-28, 2010.

FARINATTI, P. T. V.; FERREIRA, M.S. Saúde, promoção da saúde e educação física: conceitos, princípios e aplicações. Rio de Janeiro: EdUERJ, 2006.

FREIRE, P. Pedagogia do oprimido. 41. ed. Rio de Janeiro: Paz e Terra, 2005.

FREIRE, M. Educação física escolar: desafios e compromissos de uma experiência crítica e democrática. Cadernos de Formação RBCE, Rio de Janeiro, v. 4, n. 2, 2014. Disponível em: http://revista.cbce.org.br/index.php/cadernos/article/view/1824/967. Acesso em: 19 abr. 2018. 
GAZZINELLI, M. F. et al. Educação em saúde: conhecimentos, representações sociais e experiências da doença. Cadernos de Saúde Pública, Rio de Janeiro, v. 21, p. 200-206, 2005. Doi: 10.1590/S0102-311X2005000100022.

KNUTH, A. G.; AZEVEDO, M. R.; RIGO, L. C. A inserção de temas transversais em saúde nas aulas de educação física. Rev Bras Ativ Fis Saúde, Florianópolis, v. 12, n. 3, p. 73-78, 2007. Disponível em: http://repositorio.furg.br/handle/1/1253. Acesso em: 10 abr. 2018.

MEYER, D. E. E. et al. "Você aprende. A gente ensina?": interrogando relações entre educação e saúde desde a perspectiva da vulnerabilidade. Cadernos de Saúde Pública, Rio de Janeiro, v. 22, p. 1.335-1.342, 2006. Disponível em: https://www.scielosp.org/scielo.php?pid=S0102-

311X2006000600022\&script=sci_arttext\&tlng=es. Acesso em 20 mai 2019.

MOREIRA, J. et al. Educação popular em saúde: a educação libertadora mediando a promoção da saúde e o empoderamento. Revista Contrapontos, Itajaí, v. 7, n. 3, p. 507-521, 2009. Disponível em: www6.univali.br/seer/index.php/rc/article/view/920/775. Acesso em 20 mai 2019.

MORSCHBACHER, M.; MARQUES, C. L. S. Distanciamentos e aproximações entre a educação física escolar e as propostas pedagógicas críticas: o caso da teoria críticoemancipatória e didática comunicativa. Movimento, Porto Alegre, v. 19, n. 2, p. 149-166, 2013. Doi: 10.22456/1982-8918.29451.

OLIVEIRA, A. A. B. O tema saúde na educação física escolar: uma visão patogênica ou salutogênica? In: KUNZ, E.; HILDEBRANDT-STRAMANN, R. Intercâmbios científicos internacionais em educação física e esportes. Ijuí: UNIJUI, 2004. p. 241-259.

OLIVEIRA, V. J. M.; GOMES, I. M.; BRACHT, V. Educação para a saúde na educação física escolar: uma questão pedagógica! Cadernos de formação RBCE, Rio de Janeiro, v. 5, n. 2, 2015. Doi: 10.4025/reveducfis.v26i2.25600.

ORGANIZAÇÃO PANAMERICANA DE SAÚDE. Escolas promotoras da saúde: fortalecimento da iniciativa regional. Estratégias e linhas de ação 2003-2012. Washington: OPS/OMS. 2003. Disponível em: http://www.cepis.opsoms.org/bvsdeescuelas/fulltext/EPSportu.pdf. Acesso em: 17 mar. 2018.

VERDI, M.; CAPONI, S. Reflexões sobre a promoção da saúde numa perspectiva bioética. Texto \& Contexto Enfermagem, Florianópolis, v. 14, n. 1, 2005. Doi:10.1590/S0104-07072005000100011.

VIEIRA, A. G. et al. A escola enquanto espaço produtor da saúde de seus alunos. Revista Ibero-Americana de Estudos em Educação, Araraquara, v. 12, n. esp., p. 916-932, 2017. Doi: 10.21723 /riaee.

Submetido em 27 de julho de 2019.

Aprovado em 12 de outubro de 2019. 